\title{
Effect of Face Mask Design and Bias Flow on Rebreathing During Noninvasive Ventilation
}

\author{
Davide Signori, Giacomo Bellani, Serena Calcinati, Alice Grassi, Nicolò Patroniti, and \\ Giuseppe Foti
}

\begin{abstract}
BACKGROUND: Noninvasive ventilation (NIV) is used to treat respiratory failure because it reduces the risks of endotracheal intubation and postextubation respiratory failure. A wide range of different interfaces is available, but concerns exist about rebreathing. This study evaluated a total face mask with a 2 -limb ventilation circuit and separate access for inflow and outflow gas, which was developed to reduce rebreathing. METHODS: In a bench test, a standard total face mask (with a single connector to the ventilation circuit) and the modified total face mask were applied to a mannequin connected to an active breathing simulator. A known $\mathrm{CO}_{2}$ flow $\left(\dot{\mathrm{V}}_{\mathrm{CO}_{2}}\right)$ was delivered to the mannequin's trachea. We tested the following settings: CPAP with the mechanical PEEP valve set at $8 \mathrm{~cm} \mathrm{H} \mathrm{H}_{2} \mathrm{O}$ (with 60 and $90 \mathrm{~L} /$ min continuous flow) and pressure support of 6 and $12 \mathrm{~cm} \mathrm{H}_{2} \mathrm{O}$ (with 2 and $15 \mathrm{~L} / \mathrm{min}$ bias flow). The settings were tested at simulated breathing frequencies of 15 and 30 breaths/min and with $\dot{\mathrm{V}}_{\mathrm{CO}_{2}}$ of 200 and $300 \mathrm{~mL} / \mathrm{min}$. The active simulator generated a tidal volume of $500 \mathrm{~mL}$. Airway pressure, air flow, $\mathrm{CO}_{2}$ concentration, and $\mathrm{CO}_{2}$ flow as the product of air flow and $\mathrm{CO}_{2}$ were recorded. RESULTS: The mean volume of $\mathrm{CO}_{2}$ rebreathed and the minimum $\mathrm{CO}_{2}$ inspiratory concentration were significantly lower with the modified mask than with the standard mask. The $15 \mathrm{~L} / \mathrm{min}$ bias flow significantly decreased rebreathing with the DiMax0 mask, whereas it had no effect with the traditional mask. CONCLUSIONS: A face mask with a two-limb ventilation circuit and separate access for inflow and outflow gas reduces rebreathing during NIV. The addition of bias flow enhances this effect. Further studies are required to verify the clinical relevance. Key words: noninvasive ventilation; rebreathing; face mask; bias flow; carbon dioxide clearance. [Respir Care 2019;64(7):793-800. (C) 2019 Daedalus Enterprises]
\end{abstract}

\section{Introduction}

Noninvasive ventilation (NIV) is commonly used as a first-line treatment for acute and chronic respiratory fail-

\footnotetext{
Drs Signori, Bellani, Grassi, and Foti are affiliated with the School of Medicine and Surgery, University of Milan-Bicocca, Monza, Italy. Drs Bellani, Calcinati, Grassi, and Foti are affiliated with the Department of Emergency and Intensive Care, San Gerardo Hospital, Monza, Italy. Dr Patroniti is affiliated with the Department of Surgical and Integrated Diagnostical Science, University of Genoa, San Martino Hospital, Genoa, Italy.

Dr Calcinati presented a version of this study at SMART meetings held in May 2017 and May 2018 in Milan, Italy. Dr Patroniti presented a version of this study at the European Society of Intensive Care Medicine meeting, held on September 23-27, 2017, in Vienna, Austria.
}

Drs Bellani, Patroniti, and Foti disclose relationships with Dimar. The other authors have disclosed no conflicts of interest. ure in certain patients (eg, COPD exacerbation, acute cardiogenic pulmonary edema). ${ }^{1-3} \mathrm{NIV}$ represents a valid strategy to reduce endotracheal intubation rates and to treat postextubation respiratory failure. ${ }^{4}$ Hypercapnic patients benefit considerably from NIV, which increases alveolar ventilation, decreases $\mathrm{P}_{\mathrm{aCO}}$, and unloads the respiratory muscles. ${ }^{5-7}$

However, depending on the underlying disease and disease severity, NIV failure in critically ill patients ranges

\footnotetext{
Supplementary material related to this paper is available at http:// www.rcjournal.com.

Correspondence: Giacomo Bellani MD PhD, University of MilanBicocca, School of Medicine and Surgery, Via Cadore 48, Monza, Italy. E-mail: giacomo.bellani1@unimib.it.
}

DOI: $10.4187 /$ respcare. 06269 
from $5 \%$ to $60 \%,{ }^{8}$ and interface-related problems have been identified among the possible causes of failure; air leaks, excessive pressure on the face, claustrophobia, skin lesions on the nasal bridge, facial pain, and oronasal dryness could lead to early discontinuation of NIV.9-11

Some concerns have also been raised regarding the occurrence of rebreathing. ${ }^{12}$ The relevance of rebreathing was noted in a bench study in which the rebreathed volume was as much as $55 \%$ of the tidal volume $\left(\mathrm{V}_{\mathrm{T}}\right)$ during ventilation with a single-limb circuit and in the absence of a non-rebreathing valve. ${ }^{13}$ When translated to the clinical setting, the same ventilator circuit in the absence of a non-rebreathing valve led to a higher minute ventilation and work of breathing than that of a circuit with a nonrebreathing valve at the same $\mathrm{P}_{\mathrm{aCO}_{2}}$. Air leaks are one of the most studied NIV-related issues" ${ }^{14}$ : in fact, while "intentional leaks" are deliberately generated in the system to avoid rebreathing, ${ }^{15}$ "unintentional leaks" (eg, occurring between the mask and the skin, or through the mouth during nasal ventilation) can affect the effectiveness of ventilation, leading to asynchronies and NIV discontinuation. ${ }^{16}$ Therefore, a balance between modest leaks and low rebreathing has to be found, and the choice of the interface to deliver NIV is critical. In a recent trial, a helmet interface was shown to be superior to a face mask in delivering NIV to subjects with ARDS. ${ }^{17}$ The high gas flow in the helmet could contribute to reduced rebreathing; this may be one of the possible mechanisms of the findings of Patel et al. ${ }^{17,18}$ In fact, the use of a face mask to deliver NIV might have the drawback of increased dead space due to the inner volume of the mask and the use of a singlelimb connection to the ventilator circuit shared by the inflow and outflow. ${ }^{19,20}$ The intermittent and limited fresh gas flow may not be enough for $\mathrm{CO}_{2}$ clearance from inside the mask. ${ }^{12,21}$ One of the solutions to this problem could be the addition of bias flow (a continuous flow of gas inside the ventilatory system during the whole respiratory cycle); a bias flow, however, will only be effective in the presence of air leaks because it would otherwise circulate around the circuit $\mathrm{Y}$-piece without washing out the inner mask. ${ }^{22}$

Different types of mask were tested in a previous study to verify the effect of mask design on rebreathing. The use of a smaller mask with an exhalation port located within the mask (as opposed to a valve located on the ventilator circuit) showed the best performance. ${ }^{23}$ However, this study was criticized because the reduction in $\mathrm{CO}_{2}$ volume rebreathing, though statistically significant, was very small (2-3.5 mL/breath) and not clinically relevant. ${ }^{24}$

In this study, we compared a new total face mask design aimed to reduce rebreathing with 2 different ports, one for the inflow fresh gas and one for the outflow exhaled gas, to a standard mask with a single gas port. We secondarily studied the effect of air leaks on rebreathing, and we tested

\section{QUICK LOOK}

\section{Current knowledge}

Noninvasive ventilation (NIV) is commonly used to treat respiratory failure. The delivery of NIV, during both continuous-flow CPAP and pressure support ventilation, is associated with a relevant failure rate, possibly due to rebreathing, which increases the patient's respiratory load. Rebreathing is decreased by the presence of air leaks, but the interface used to deliver NIV is another determinant.

\section{What this paper contributes to our knowledge}

In a bench model, rebreathing was mitigated by a total face mask design with separate ports for inflow and outflow. The effectiveness of the new mask design in reducing rebreathing was increased in the presence of higher flow CPAP and when bias flow was provided by the mechanical ventilator during NIV. In the presence of air leaks, the new face mask design was still effective in reducing rebreathing.

the effectiveness of the new mask design in the presence of leaks.

\section{Methods}

\section{Study Protocol}

In this bench study, which was conducted in the laboratory of Dimar S.R.L. in Medolla, Italy, an active lung simulator (ASL 5000, Ingmar Medical, Pittsburgh, Pennsylvania) was connected by a tube to the mouth of a mannequin face to compare 2 total-face mask configurations (Fig. 1 illustrates the masks design and the experimental setting). The standard mask had a single connector for inflow/outflow gases (DiMax, Dimar, Medolla, Italy, inner volume $660 \mathrm{~mL}$ ), and the modified mask had 2 different connectors for inflow and outflow gases (DiMax0, Dimar, inner volume $700 \mathrm{~mL}$ ).

Each mask was connected to a free-flow CPAP or to an ICU ventilator (Puritan Bennett 840, Covidien) through standard circuits. A known $\mathrm{CO}_{2}$ flow was delivered to the mannequin's trachea to simulate $\mathrm{CO}_{2}$ production $\left(\dot{\mathrm{V}}_{\mathrm{CO}_{2}}\right)$ of $200 \mathrm{~mL} / \mathrm{min}$ or $300 \mathrm{~mL} / \mathrm{min}$ (Bronkhorst High-Tech B.V., Ruurlo, The Netherlands). To avoid confounders, air loss was minimized by sealing each mask to the mannequin face with silicone for the first set of experiments. Then, to simulate a more realistic scenario similar to those found in clinical settings, some of the experiments were repeated without silicone, which allowed a leak of approximately $20 \%$ on the set $\mathrm{V}_{\mathrm{T}}$. 

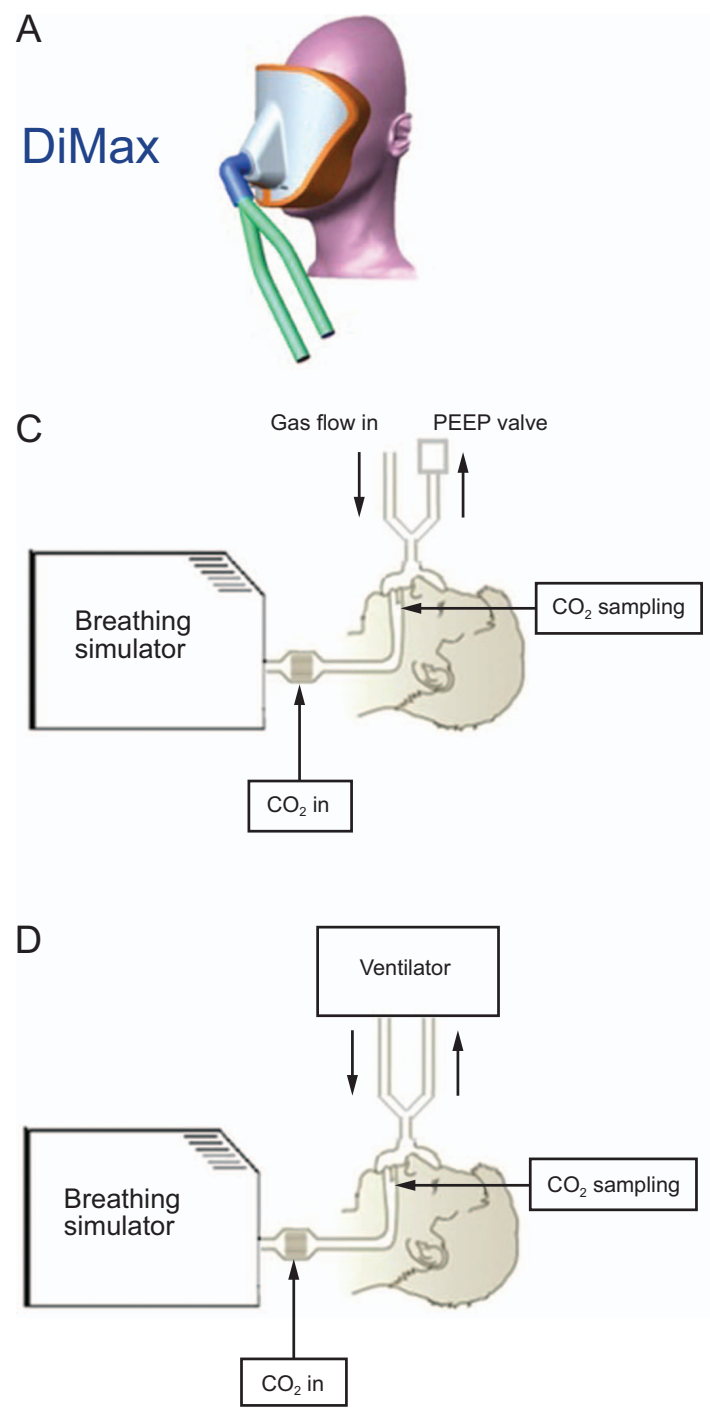

B
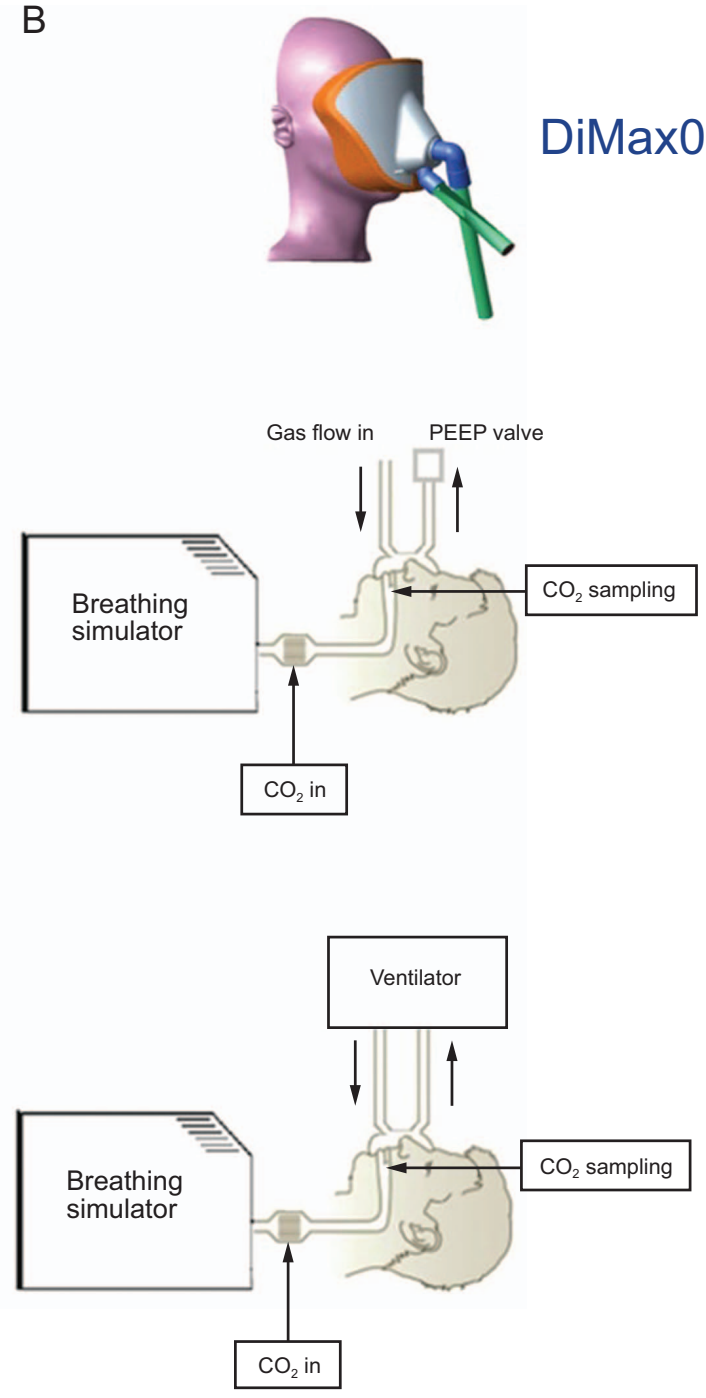

Fig. 1. Design and experimental settings for the face masks. (A) Standard mask design (DiMax). (B) Modified mask (DiMax0). (C) CPAP settings and (D) pressure support ventilation settings.

\section{Data Acquisition}

We tested 2 ventilation settings. The first was continuous-flow CPAP, which consisted of a continuous fresh gas flow of $60 \mathrm{~L} / \mathrm{min}$ or $90 \mathrm{~L} / \mathrm{min}$ in the tested face mask through the inspiratory branch and a mechanical PEEP valve (700/6336, Dimar) set at $8 \mathrm{~cm} \mathrm{H}_{2} \mathrm{O}$ on the expiratory limb. The second setting was pressure support ventilation (PSV), in which the tested face mask was connected to the ventilator (Puritan Bennet 840 ) by the inspiratory and expiratory limb set to deliver a pressure support of $6 \mathrm{~cm} \mathrm{H}_{2} \mathrm{O}$ and $12 \mathrm{~cm} \mathrm{H}_{2} \mathrm{O}$, with a minimum bias flow of $2 \mathrm{~L} / \mathrm{min}$ or a maximum bias flow of $15 \mathrm{~L} / \mathrm{min}$. PEEP was kept constant at $4 \mathrm{~cm} \mathrm{H}_{2} \mathrm{O}$ in all conditions.

Each of the aforementioned settings was tested at a simulated breathing frequency of 15 breaths/min and
30 breaths/min (see the supplementary materials at http:// www.rcjournal.com). A negative inspiratory pressure swing of the simulator was set to generate a constant $\mathrm{V}_{\mathrm{T}}$ of $500 \mathrm{~mL}$ in all conditions with an inspiratory-expiratory ratio set at 1:2. We hypothesized that the expired $\mathrm{CO}_{2}$ would be reduced by about $50 \%$ of the amount if the simulated breathing frequency was doubled.

\section{Measurements}

Sensors were placed at the airway opening to measure flow (SpiroQuantA+, Envitec, Lohne, Germany), pressure (First Sensor, Berlin, Germany), and mainstream $\mathrm{CO}_{2}$ concentration (Dittrich Elektronic, Baden Baden, Germany). All of the signals were digitalized at a sampling rate of $100 \mathrm{~Hz}$ and recorded (Labview, National Instru- 


\section{Total Face Mask Design and Rebreathing}

ments Italy, Milano, Italy). Curves were analyzed offline (Powerlab, ADinstruments, Sydney, Australia). The $\mathrm{CO}_{2}$ flow inspired and expired by the simulator was calculated as the instantaneous product of $\mathrm{CO}_{2}$ concentration and total airway flow. We then derived the following parameters on a breath-by-breath basis: $\mathrm{V}_{\mathrm{T}}$, minimum inspiratory pressure (indicator of pneumatic performance), inspired (rebreathed) $\mathrm{CO}_{2}$ volume, and functional dead space, which indicates the amount of $\mathrm{V}_{\mathrm{T}}$ "lost" to gas exchange due to rebreathing. The word "functional" emphasizes that this represents the fraction of $\mathrm{V}_{\mathrm{T}}$ wasted due to rebreathing and represents the volume of gas, with a $\mathrm{CO}_{2}$ concentration equal to the mixed expiratory $\mathrm{CO}_{2}$, which contains the amount of $\mathrm{CO}_{2}$ rebreathed:

\section{$\mathrm{CO}_{2}$ rebreathed volume/ $\left(\mathrm{CO}_{2}\right.$ exhaled volume $\left./ \mathrm{V}_{\mathrm{T}}\right)$}

For example, if the volume of rebreathed $\mathrm{CO}_{2}$ were $5 \mathrm{~mL}$, the volume of exhaled $\mathrm{CO}_{2}$ were $20 \mathrm{~mL}$, and the $\mathrm{V}_{\mathrm{T}}$ were $500 \mathrm{~mL}$, then the functional dead space would be $125 \mathrm{~mL}$. The volume of rebreathed $\mathrm{CO}_{2}$ is expressed as a percentage of the calculated $\dot{\mathrm{V}}_{\mathrm{CO}_{2}}$. Three or four breaths were needed by the simulator to adapt to ventilator settings, then a steady state was reached and the amount of rebreathing was stable in each breath, with no accumulation over time. For each condition, we sampled 30-40 breaths. Examples of the curves are reported in the data supplement (see the supplementary materials at http://www. rcjournal.com).

\section{Statistical Analysis}

All data are expressed as mean $\pm \mathrm{SD}$. Two-way analysis of variance for repeated measures with Tukey's post hoc analysis was used to compare airway pressure, inspired $\mathrm{CO}_{2}$, and rebreathed $\mathrm{CO}_{2}$ between the 2 masks when different ventilation settings were used (CPAP with 2 different flows, PSV with or without bias flow). The same statistical test was used to compare different ventilation settings within the same mask. $P<.05$ was considered statistically significant. Statistical analysis was performed using SPSS v.24.0 (IBM, Armonk, New York).

\section{Results}

We tested the same ventilator settings with a $\dot{\mathrm{V}}_{\mathrm{CO}_{2}}$ of $200 \mathrm{~mL} / \mathrm{min}$ and $300 \mathrm{~mL} / \mathrm{min}$. All results were obtained with $\dot{\mathrm{V}}_{\mathrm{CO}_{2}}=300 \mathrm{~mL} / \mathrm{min}$. The results obtained with a $\dot{\mathrm{V}}_{\mathrm{CO}_{2}}=200 \mathrm{~mL} / \mathrm{min}$ are comparable at all settings (see the supplementary materials at http://www.rcjournal.com).

\section{Calculated $\dot{\mathrm{V}}_{\mathrm{CO}_{2}}$}

The values of calculated $\dot{\mathrm{V}}_{\mathrm{CO}_{2}}$ for the 2 masks and at the different ventilation settings are shown in the data supple- ment (see the supplementary materials at http://www. rcjournal.com). The calculated $\dot{\mathrm{V}}_{\mathrm{CO}_{2}}$ was similar to the set $\dot{\mathrm{V}}_{\mathrm{CO}_{2}}(300 \mathrm{~mL} / \mathrm{min})$.

\section{Inspiratory Pressure Drop}

Minimum pressure during inspiration is shown in the data supplement (see the supplementary materials at http:// www.rcjournal.com). This parameter allows comparison between the pneumatic performances of the 2 masks by expressing the capacity of the mask to maintain a constant pressure during the overall respiratory cycle. A pressure drop below the set level of PEEP is an indicator of poor pneumatic performance or insufficient flow. During CPAP, in both masks and with both flows and simulated breathing frequencies, the minimum inspiratory pressure was slightly lower than PEEP, with this effect being more pronounced with the simulated breathing frequency of 30 breaths $/ \mathrm{min}$. In PSV, the 2 masks did not show a systematic difference in pressure drop. As expected, the increase of bias flow (which also affects trigger sensitivity for the specific ventilator used) led to an increase in the inspiratory pressure drop.

\section{Amount of Rebreathing}

With continuous-flow CPAP, the DiMax0 mask reduced the amount of rebreathing in all conditions tested by about $90 \%$ with a simulated breathing frequency of 15 breaths/min and by $75 \%$ with a simulated breathing frequency of 30 breaths/min compared to the DiMax mask. At a simulated breathing frequency of 30 breaths $/ \mathrm{min}$, increasing the CPAP flow from $60 \mathrm{~L} / \mathrm{min}$ to $90 \mathrm{~L} / \mathrm{min}$ significantly reduced rebreathing within the same mask, as expected, although the effect was more pronounced with the DiMax0 mask (Fig. 2).

During PSV, at both $6 \mathrm{~cm} \mathrm{H}_{2} \mathrm{O}$ and $12 \mathrm{~cm} \mathrm{H}_{2} \mathrm{O}$ and without bias flow, the DiMax0 mask allowed a $20 \%$ reduction of rebreathing, and this benefit disappeared when the simulated breathing frequency was set at $30 \mathrm{breaths} / \mathrm{min}$. However, the addition of a bias flow of $15 \mathrm{~L} / \mathrm{min}$ was effective in reducing rebreathing with the DiMax0 mask in comparison with the DiMax mask. Again, this effect was greater at lower simulated breathing frequencies (15 breaths/min), where the DiMax0 mask reduced rebreathing by $65 \%$ versus the DiMax mask. When the simulated breathing frequency was set at 30 breaths/min, rebreathing was reduced by about $15 \%$ during PSV at both $6 \mathrm{~cm} \mathrm{H}_{2} \mathrm{O}$ and $12 \mathrm{~cm} \mathrm{H}_{2} \mathrm{O}$ (Fig. 2).

The findings were similar for the minimum concentration of $\mathrm{CO}_{2}$ measured during inspiration (Table 1), and confirmed by the calculated differences in functional dead space (see the supplementary materials at http://www.rcjournal.com). 

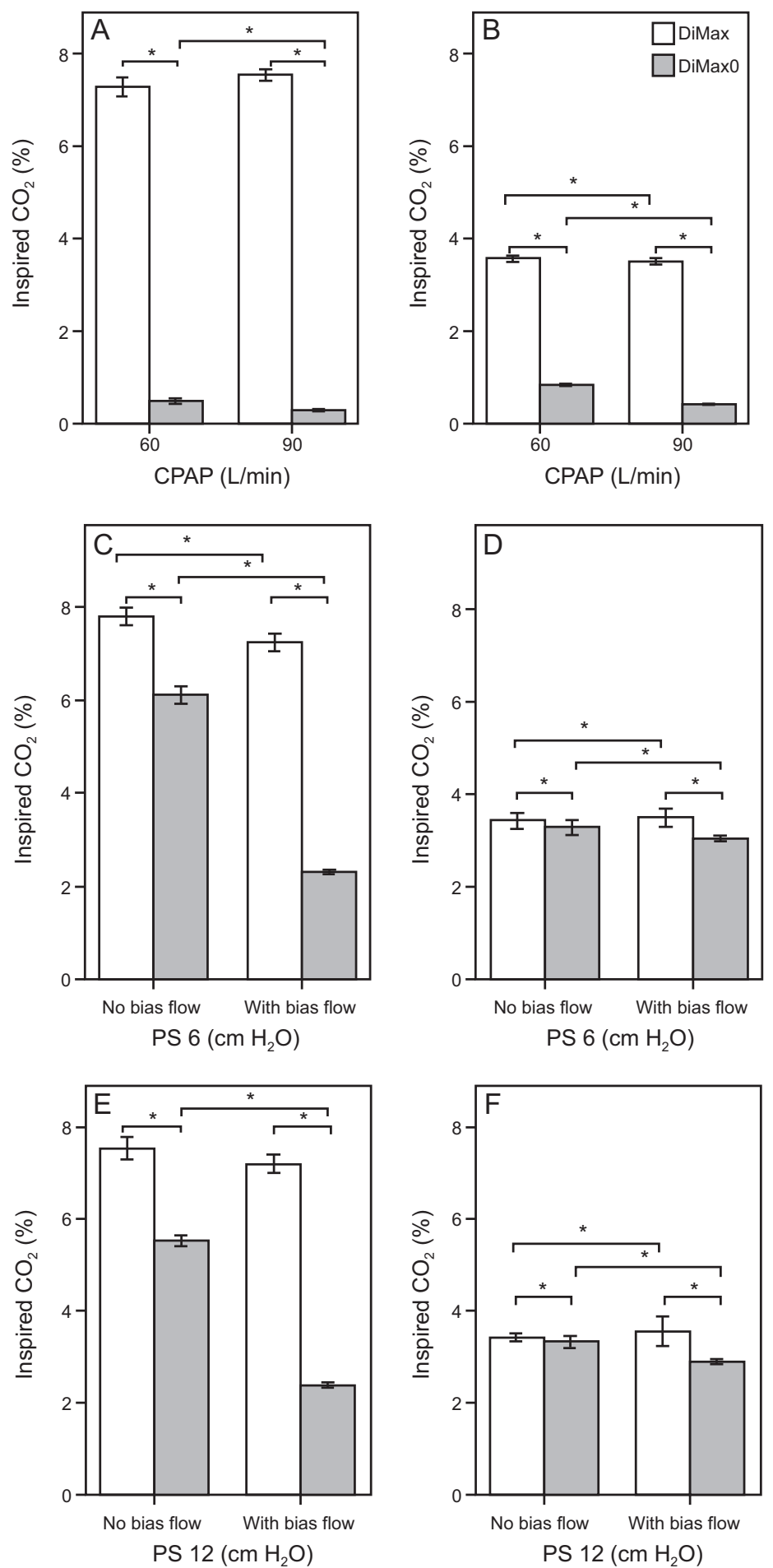

Fig. 2. Inspired $\mathrm{CO}_{2}$ per breath, expressed as $\%$ of $\dot{\mathrm{V}}_{\mathrm{CO}_{2}}$. $A$ and $\mathrm{B}$ : during $\mathrm{CPAP}, \mathrm{C}$ and $\mathrm{D}$ : during pressure support $(\mathrm{PS})$ of $6 \mathrm{~cm} \mathrm{H}_{2} \mathrm{O} \pm$ bias flow $15 \mathrm{~L} / \mathrm{min}$, and $\mathrm{E}$ and $\mathrm{F}$ : during $\mathrm{PS}$ of $12 \mathrm{~cm} \mathrm{H} \mathrm{H}_{2} \mathrm{O} \pm$ bias flow $15 \mathrm{~L} / \mathrm{min}$. Simulated breathing frequency $15 \mathrm{breaths} / \mathrm{min}(\mathrm{A}, \mathrm{C}$, and $\mathrm{E})$ and 30 breaths/min (B, D, and F). Error bars indicate SD. * $P<.001$.

\section{Amount of Rebreathing When Leaks Are Added}

To test the DiMax0 mask in a scenario similar to those seen clinically, we allowed a $20 \%$ leak of the set $\mathrm{V}_{\mathrm{T}}$
(Fig. 3). First, we recorded the effect of the leaks on rebreathing, and we found that, as expected, leaks significantly reduced rebreathing within the same mask in each ventilation setting. When comparing the 2 masks, the ef- 
Total Face Mask Design and Rebreathing

Table 1. Minimum Inspiratory $\mathrm{CO}_{2}$ Concentration Compared Between Different Face Masks and Gas Flows

\begin{tabular}{|c|c|c|c|c|c|c|c|}
\hline \multirow{3}{*}{ Setting } & \multirow{3}{*}{$\begin{array}{l}\text { Breathing } \\
\text { Frequency, } \\
\text { breaths/min }\end{array}$} & \multicolumn{4}{|c|}{ Minimum Inspiratory $\mathrm{CO}_{2}$ concentration (\%), Mean (SD) } & \multirow{3}{*}{ Effect of: } & \multirow{3}{*}{$P$} \\
\hline & & \multicolumn{2}{|c|}{$\begin{array}{l}\text { CPAP } 60 \mathrm{~L} / \mathrm{min} \text { or } \\
\text { PSV Without Bias Flow }\end{array}$} & \multicolumn{2}{|c|}{$\begin{array}{l}\text { CPAP } 90 \mathrm{~L} / \mathrm{min} \text { or } \\
\text { PSV With Bias Flow }\end{array}$} & & \\
\hline & & DiMax & DiMax0 & DiMax & DiMax0 & & \\
\hline \multirow[t]{6}{*}{ CPAP } & 15 & $2.82(0.12)$ & $0.06(0.01)$ & $2.70(0.17)$ & $0.03(0.004)$ & Face mask & $<.001$ \\
\hline & & & & & & Gas flow & $<.001$ \\
\hline & & & & & & Interaction & $<.001$ \\
\hline & 30 & $1.37(0.05)$ & $0.28(0.01)$ & $1.39(0.06)$ & $0.10(0.01)$ & Face mask & $<.001$ \\
\hline & & & & & & Gas flow & $<.001$ \\
\hline & & & & & & Interaction & $<.001$ \\
\hline \multirow[t]{6}{*}{ PSV $6 \mathrm{~cm} \mathrm{H}_{2} \mathrm{O}$} & 15 & $3.12(0.14)$ & $1.64(0.06)$ & $2.68(0.14)$ & $0.61(0.02)$ & Face mask & $<.001$ \\
\hline & & & & & & Bias flow & $<.001$ \\
\hline & & & & & & Interaction & $<.001$ \\
\hline & 30 & $1.43(0.06)$ & $1.39(0.04)$ & $1.47(0.06)$ & $0.88(0.03)$ & Face mask & $<.001$ \\
\hline & & & & & & Bias flow & $<.001$ \\
\hline & & & & & & Interaction & $<.001$ \\
\hline \multirow[t]{6}{*}{ PSV $12 \mathrm{~cm} \mathrm{H}_{2} \mathrm{O}$} & 15 & $2.77(0.13)$ & $1.65(0.07)$ & $2.85(0.13)$ & $0.57(0.02)$ & Face mask & $<.001$ \\
\hline & & & & & & Bias flow & $<.001$ \\
\hline & & & & & & Interaction & $<.001$ \\
\hline & 30 & $1.42(0.06)$ & $1.37(0.05)$ & $1.42(0.06)$ & $0.87(0.03)$ & Face mask & $<.001$ \\
\hline & & & & & & Bias flow & $<.001$ \\
\hline & & & & & & Interaction & $<.001$ \\
\hline
\end{tabular}

Measurements made during the $\dot{\mathrm{V}}_{\mathrm{CO}_{2}} 300 \mathrm{ml} / \mathrm{min}$ setting.

$P$ values determined with analysis of variance.

fect of the DiMax0 mask on rebreathing was, as expected, blunted compared to the setting without leaks. Nevertheless, the DiMax0 mask was able to significantly reduce rebreathing by $80 \%$ in CPAP with a flow of $90 \mathrm{~L} / \mathrm{min}$, by $30 \%$ in $\mathrm{PSV}$ at $6 \mathrm{~cm} \mathrm{H}_{2} \mathrm{O}$ with bias flow, and by $10 \%$ in PSV at $12 \mathrm{~cm} \mathrm{H}_{2} \mathrm{O}$ with bias flow, confirming the data that the addition of bias flow greatly enhanced the effectiveness of the DiMax0 mask. Figure 3 shows the results obtained with the simulated breathing frequency set at 30 breaths/min. The experiment performed with the simulated breathing frequency set at 15 breaths/min is shown in the online data supplement (see the supplementary materials at http://www.rcjournal.com).

\section{Discussion}

The main result of this study can be summarized as follows: separate ports for inflow and outflow substantially reduced rebreathing in a total face mask, especially during CPAP and PSV with bias flow and no leaks.

In this bench study, we found that the amount of $\mathrm{CO}_{2}$ inhaled at every breath can be as high as $6 \%$ of the $\dot{\mathrm{V}}_{\mathrm{CO}_{2}}$ (about $18 \mathrm{~mL}$ for a $\dot{\mathrm{V}}_{\mathrm{CO}_{2}}$ of $300 \mathrm{~mL}$ ), an amount almost double the results reported by Schettino et $\mathrm{al}^{23}$ when using a total face mask (10.4 mL/breath). This may be clinically relevant, particularly in patients with high ventilation de- mand and limited muscle reserve, and this likely contributes to the high incidence of NIV failure reported in more severe patients. Of relevance, rebreathing is not only an issue in hypercapnic patients, but also in hypoxemic patients, who normally exhibit a high respiratory drive and a normal/low $\mathrm{P}_{\mathrm{aCO}_{2}}{ }^{25}$; in these patients, rebreathing would represent an adjunctive ventilatory stimulus, further increasing respiratory drive and minute ventilation.

As stated, the separation of the inflow and outflow ports allowed a significant reduction in the amount of rebreathing. With a standard mask design, the air flow bypasses the volume of the entire mask (flowing around the Y-piece of the ventilator circuit), while with the separate port design, fresh air flow is forced into the mask dead space. This phenomenon is attenuated by higher breathing frequencies that reduce expiratory time, during which $\mathrm{CO}_{2}$ washout occurs.

To obtain significant $\mathrm{CO}_{2}$ clearance from the mask, even with a separate port design, an adequate amount of fresh gas must flow through the system; the advantage is almost negligible at the lowest bias flows $(2 \mathrm{~L} / \mathrm{min})$, but it becomes evident when this is increased to the highest flow allowed by the ventilator ( $15 \mathrm{~L} / \mathrm{min}$ of fresh gas flow). Finally, the high flows during CPAP (60-90 L/min of fresh gas flow) allow an adequate $\mathrm{CO}_{2}$ clearance even at higher breathing frequencies. Because not all mechanical 


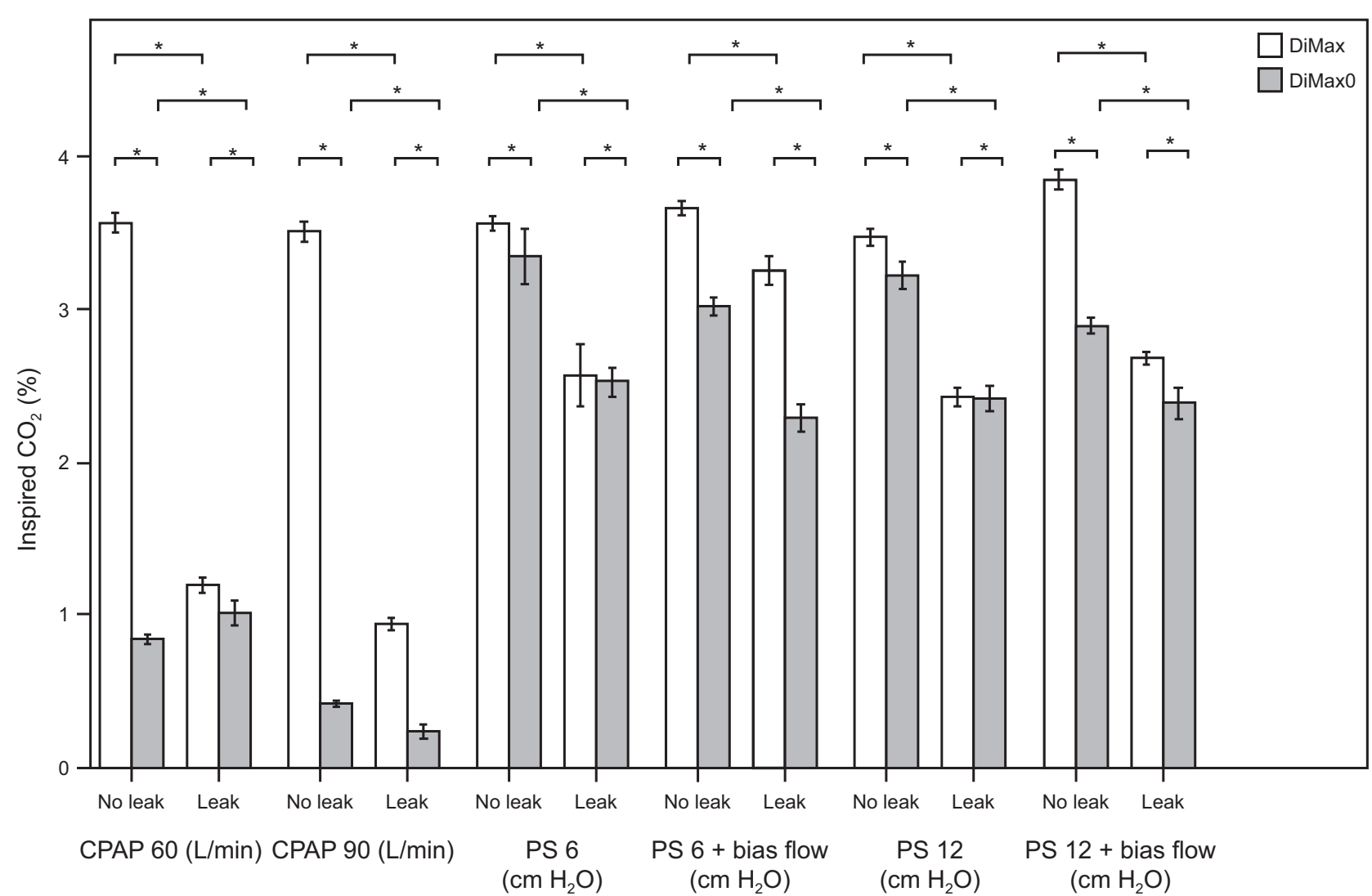

Fig. 3. Inspired $\mathrm{CO}_{2}$ per breath, expressed as \% of $\dot{\mathrm{V}}_{\mathrm{CO}_{2}}$, with simulated breathing frequency set at 30 breaths/min, after adding a $20 \%$ leak on tidal volume $\left(\dot{V}_{\mathrm{CO}_{2}}=300 \mathrm{~mL} / \mathrm{min}\right)$. Error bars indicate SD. PS = pressure support. ANOVA results: $P<.001$ for face-mask effect and for air-leak effect, interaction $P<.001$ in each ventilation condition. ${ }^{*} P<.001$.

ventilators allow an arbitrary increase in bias flow settings, the clinical applicability of these findings might be limited depending on the specific devices available at each center.

Each system for NIV also affects a patient's work load, which we estimated as the pressure drop during inspiration. During CPAP, this indicates that the set flow was not enough to maintain stable PEEP while inspiration was starting, whereas during PSV, the reduction in inspiratory pressure is the trigger for the ventilator to deliver the set pressure support. The 2 masks in this study showed slightly different pneumatic performances, without a consistent difference one way or another. Moreover, although statistically significant due to the lack of variability (as expected in a bench setting), the differences were modest and likely are not clinically relevant. For this reason, we consider the masks equivalent from this perspective.

Due to the specific type of ventilator used, the application of a higher bias flow also affected the triggering sensitivity. Hence, despite a better $\mathrm{CO}_{2}$ washout, higher bias flow resulted in a greater pressure drop during inspiration. This problem can be solved easily with the use of ventilators that allow the operator to set bias flow and trigger sensitivity independently.
Leaks (whether intentional or unintentional) are often advocated as a workaround to decrease rebreathing because these ultimately increase the fresh gas flowing through the mask. We confirm this knowledge, but our results also show that, as opposed to continuous-flow CPAP, the efficacy of leaks during PSV is limited because the ventilator will deliver additional gas flow only to compensate for the leaks. This means that the gas leaving the face mask through the leaks will ultimately be lower. Moreover, during PSV leaks might worsen patient-ventilator synchrony, possibly offsetting some of the advantages of the improved $\mathrm{CO}_{2}$ clearance. As a side result, our study also suggests effective ways to reduce rebreathing during a CPAP or NIV trial while using the interfaces already available on the market: a higher flow should be used during CPAP, and a ventilator that allows a high bias flow setting should be chosen to deliver NIV.

In this study, we attempted to simulate different types of ventilatory assistance: first we simulated CPAP with a "moderate" PEEP level of $8 \mathrm{~cm} \mathrm{H}_{2} \mathrm{O}$, which could be used in a patient with obstructive apnea or mild hypoxia. Then we tested 2 different levels of support: $6 \mathrm{~cm} \mathrm{H}_{2} \mathrm{O}$ and $12 \mathrm{~cm} \mathrm{H}_{2} \mathrm{O}$, as one would use for increasing levels of respiratory distress, 


\section{Total Face Mask Design and Rebreathing}

with a modest PEEP of $4 \mathrm{~cm} \mathrm{H}_{2} \mathrm{O}$ to avoid an unrealistically high peak inspiratory pressure. We also simulated 2 extreme breathing frequencies, leading to different minute ventilations and peak inspiratory flows, finding consistent results in all of the different combinations.

Although promising, the results of this bench study do not allow us to draw definitive conclusions on the effect that this modified face mask design could have on a patient's breathing effort, NIV efficacy, and ultimate clinical outcomes. Clinical studies are needed to confirm the relevance of these findings. If confirmed, the implementation of a NIV application with this new mask could be costeffective. The novel mask has the same cost as the standard mask from the same manufacturer. In addition, reducing rebreathing will ultimately lead to a higher rate of NIV success and less intubation, with an overall advantage for both patients and hospital costs.

\section{Conclusion}

The delivery of NIV, during both continuous-flow CPAP and PSV, is associated with clinically relevant rebreathing, which is decreased by the presence of leaks. Rebreathing can be mitigated by a face mask design with separate ports for inflow and outflow; this design is effective if a sufficient amount of additional bias flow is provided by a continuous-flow system or by the mechanical ventilator.

\section{REFERENCES}

1. Ambrosino N, Vagheggini G. Noninvasive positive pressure ventilation in the acute care setting: where are we? Eur Respir J 2008; 31(4):874-886.

2. Nava S, Hill N. Non-invasive ventilation in acute respiratory failure. Lancet 2009;374(9685):250-259.

3. Rochwerg B, Brochard L, Elliott MW, Hess D, Hill NS, Nava S, et al. Official ERS/ATS clinical practice guidelines: noninvasive ventilation for acute respiratory failure. Eur Respir J. 2017;50(2):1602426.

4. Jaber S, Lescot T, Futier E, Paugam-Burtz C, Seguin P, Ferrandiere M, et al. Effect of Noninvasive ventilation on tracheal reintubation among patients with hypoxemic respiratory failure following abdominal surgery: a randomized clinical trial. JAMA 2016;315(13):1345-1353.

5. Brochard L, Mancebo J, Wysocki M, Lofaso F, Conti G, Rauss A, et al. Noninvasive ventilation for acute exacerbations of chronic obstructive pulmonary disease. N Engl J Med 1995;333(13):817-822.

6. Kramer N, Meyer TJ, Meharg J, Cece RD, Hill NS. Randomized, prospective trial of noninvasive positive pressure ventilation in acute respiratory failure. Am J Respir Crit Care Med 1995;151(6):1799-17806.

7. Keenan SP, Kernerman PD, Cook DJ, Martin CM, McCormack D, Sibbald WJ. Effect of noninvasive positive pressure ventilation on mortality in patients admitted with acute respiratory failure: a metaanalysis. Crit Care Med 1997;25(10):1685-1692.

8. Mas A, Masip J. Noninvasive ventilation in acute respiratory failure. Int J Chron Obstruct Pulmon Dis 2014;9(1):837-852.
9. Carlucci A, Richard JC, Wysocki M, Lepage E, Brochard L. Noninvasive versus conventional mechanical ventilation: an epidemiologic survey. Am J Respir Crit Care Med 2001;163(4):874-880.

10. Meduri GU, Turner RE, Abou-Shala N, Wunderink R, Tolley E. Noninvasive positive pressure ventilation via face mask. First-line intervention in patients with acute hypercapnic and hypoxemic respiratory failure. Chest 1996;109(1):179-193.

11. Soo Hoo GW, Santiago S, Williams AJ. Nasal mechanical ventilation for hypercapnic respiratory failure in chronic obstructive pulmonary disease: determinants of success and failure. Crit Care Med 1994;22(8):1253-1261.

12. Taccone P, Hess D, Caironi P, Bigatello LM. Continuous positive airway pressure delivered with a "helmet": effects on carbon dioxide rebreathing. Crit Care Med 2004;32(10):2090-2096.

13. Lofaso F, Brochard L, Touchard D, Hang T, Harf M, Isabey D. Evaluation of carbon dioxide pressure support during rebreathing ventilation with airway management system (BiPAP) devices. CHEST J 1995;108(3):772.

14. Criner GJ, Travaline JM, Brennan KJ, Kreimer DT. Efficacy of a new full face mask for noninvasive positive pressure ventilation. Chest 1994;106(4):1109-1115.

15. Médrinal C, Prieur G, Contal O, Villiot-Danger E, Doyle C, Reychler G, et al. Non-invasive ventilation: evaluation of $\mathrm{CO}_{2}$ washout by intentional leaking in three recent oronasal masks. A pilot study. Minerva Anestesiol 2015;81(5):526-532.

16. Pisani L, Carlucci A, Nava S. Interfaces for noninvasive mechanical ventilation: technical aspects and efficiency. Minerva Anestesiol 2012;78(10):1154-1161.

17. Patel BK, Wolfe KS, Pohlman AS, Hall JB, Kress JP. Effect of noninvasive ventilation delivered by helmet vs face mask on the rate of endotracheal intubation in patients with acute respiratory distress syndrome: a randomized clinical trial. JAMA 2016;315(22):2435-2441.

18. Patroniti N, Foti G, Manfio A, Coppo A, Bellani G, Pesenti A. Head helmet versus face mask for non-invasive continuous positive airway pressure: a physiological study. Intensive Care Med 2003;29(10):1680-1687.

19. Hill NS. Problems, remedies, and strategies to optimize the success of noninvasive ventilation. In: Noninvasive Positive Pressure Ventilation: Principles and Applications. Armonk, NY: Futura; 2001: 240.

20. Ou YE, Lin ZM, Hua DM, Jiang Y, Huo YT, Luo Q, et al. Evaluation of carbon dioxide rebreathing during exercise assisted by noninvasive ventilation with plateau exhalation valve. Int J COPD 2017; 12:291-298

21. Hill NS. Noninvasive interfaces: should we go to helmets? Crit Care Med 2004;32(10):2162-2163.

22. Mojoli F, Iotti GA, Gerletti M, Lucarini C, Braschi A. Carbon dioxide rebreathing during non-invasive ventilation delivered by helmet: a bench study. Intensive Care Med 2008;34(8):1454-1460.

23. Schettino GPP, Chatmongkolchart S, Hess DR, Kacmarek RM. Position of exhalation port and mask design affect $\mathrm{CO}_{2}$ rebreathing during noninvasive positive pressure ventilation. Crit Care Med 2003; 31(8):2178-2182.

24. Hill $\mathrm{N}$. What mask for noninvasive ventilation: is dead space an issue? Crit Care Med 2003;31(8):2247-2248.

25. Bellani G, Laffey JG, Pham T, Madotto F, Fan E, Brochard L, et al. Noninvasive ventilation of patients with acute respiratory distress syndrome: insights from the LUNG SAFE study. Am J Respir Crit Care Med 2017;195(1):67-77. 